\title{
Laser Butt Welding of Brass and Stainless Steel*
}

\author{
Makoto SASAKI** and Junichi IKENO*** \\ **Hitachi Metals Ltd., \\ 6010 Mikajiri, Kumagaya, Saitama, Japan \\ E-mail: makoto_sasaki@hitachi-metals.co.jp \\ ***Saitama University, \\ 255 Shimo-okubo, Sakura-ku, Saitama-shi, Saitama, Japan
}

\begin{abstract}
A welded joint formed between stainless steel and a copper-base alloy is a combination of materials with high corrosion resistance and high mechanical strength and materials with high thermal conductivity. Such a combination is suitable for applications in heat exchangers and piping design among others. Forming a welded joint between stainless steel and a copper-base alloy is difficult because the physical properties of the two metals - such as thermal conductivity and melting point - are different, and they do not form an alloy. In this study, we propose a method for butt welding brass and stainless steel using a disk YAG laser by selecting appropriate bonding conditions, and evaluate the characteristics of the joint. The results indicate that a good weld can be obtained by shifting the laser irradiation position to the brass side.
\end{abstract}

Key words: Laser Welding, YAG Laser, Brass, Stainless Steel, Shift Amount

\section{Introduction}

There has been an increasing demand to join different types of metals in order to manufacture a diverse range of products from high-specification materials. For instance, a joint formed between stainless steel and a copper-base alloy is a combination of materials with high corrosion resistance, high mechanical strength, and high thermal conductivity. Such a combination is suitable for applications in heat exchangers and piping design among others. Forming a welded joint between stainless steel and a copper-base alloy is difficult because the physical properties of the two metals - such as their thermal conductivities and melting points - are different, and they do not form an alloy. TIG welding and soldering have conventionally been used for forming joints between such metals. Recently, methods such as diffusion bonding and friction welding have been studied ${ }^{(1)}$. However, diffusion bonding has a long junction time, and thus productivity is poor. In the case of friction welding, finishing processes such as grinding are necessary. Therefore, a solution is required for these problems. Two such solutions include using a laser to weld copper alloy and stainless steel and overlapping laser welding by irradiating the laser onto stainless steels with a high laser absorption rate ${ }^{(2)}$. Moreover, the butt welding of stainless steel and brass is advantageous because overlapping laser welding restricts the shape of a pipe and its coupling. Previously, the authors proposed an efficient method for joining thin pieces of oxygen-free copper and stainless steel through mechanical linkages using a YAG laser ${ }^{(3)}$. In addition, the authors succeeded in the laser butt welding of oxygen-free copper and stainless steel with $1.5 \mathrm{~mm}$ thickness by moving the laser irradiation position to the copper side ${ }^{(4)}$. However, when it is necessary to use materials that are stronger than oxygen-free copper, a copper-base alloy such as brass with high strength should be used. Therefore, it is necessary 
to investigate the influence of zinc when brass is used because it is an alloy of copper and zinc. In this study, we attempt butt welding of brass and stainless steel using a disk YAG laser by selecting appropriate bonding conditions and then evaluate the characteristics of the welded joints.

\section{Laser butt welding method}

\subsection{Experimental method}

When brass and stainless steel are joined using a laser, it is necessary to make the two metals melt simultaneously and forcibly stir the melting pool; this is because the wettability of both iron and copper is poor. In general, the melting pool circulates because the metals quickly melt and evaporate as a result of the heat of laser welding ${ }^{(5)}$. However, it is necessary to maintain an appropriate heat balance because zinc forms bumps when the temperature of brass increases rapidly. Table 1 shows the physical properties of stainless steel and brass used in this study. Table 2 shows the heat properties of copper and zinc, which are the constituents of brass ${ }^{(6)(7)}$. Stainless steel has a higher melting point, and thus, a large amount of energy is required to fuse it. On the other hand, the light absorption rate of the laser is lower for brass, and thus, a large amount of energy is required to fuse it. Furthermore, the boiling point of zinc is lower than the fusing point of brass, as shown in Table 2. When the temperature of brass suddenly increases, zinc forms bumps and can cause blowholes. Therefore, it is necessary to maintain an appropriate heat balance while welding. The energy balance is altered by shifting the irradiation position of the laser and choosing conditions that can yield a good weld.

Table 1 Physical properties of SUS and Brass

\begin{tabular}{|c|c|c|}
\hline & $\begin{array}{c}\text { Stainless steel } \\
\text { SUS304 }\end{array}$ & $\begin{array}{r}\text { Brass } \\
\text { C2680 }\end{array}$ \\
\hline Melting point [K] & 1726 & 1216 \\
\hline Heat conductivity [W/mK] & 16 & 124 \\
\hline Laser absorption factor & 0.40 & 0.20 \\
\hline
\end{tabular}

Table 2 Heat physical property values of $\mathrm{Cu}$ and $\mathrm{Zn}$

\begin{tabular}{|c|c|c|}
\hline & copper & zinc \\
\hline Melting point [K] & 1356 & 693 \\
\hline Boiling point [K] & 2639 & 1180 \\
\hline Heat conductivity [W/mK] & 398 & 121 \\
\hline
\end{tabular}

\subsection{Experimental device}

Figure 1 is a diagrammatic representation of the experimental apparatus. The laser oscillator is a disk laser HLD1001.5 (Trumpf Co., Ltd.). The laser oscillation is in the form of a continuous wave with a beam wavelength of $1064 \mathrm{~nm}$ and the maximum laser power of $1 \mathrm{~kW}$. The optical fiber core diameter is $0.15 \mathrm{~mm}$ and the focus distance of the condenser is $200 \mathrm{~mm}$.

The materials of test piece is C2680 and SUS304. The test piece having dimensions $50 \mathrm{~mm} \times 25 \mathrm{~mm} \times 1.5 \mathrm{~mm}$ is fixed on the XY-stage and pressure is applied from the sides. The laser head is fixed at a regulated height on the Z-stage, and the test piece is welded by moving the XY-stage. Argon gas is sprayed over the weld area by an upper and lower nozzle in order to prevent oxidization.

\subsection{Evaluation method}

The following tests were performed to evaluate the welding properties.

(1) Tension test

A defect in a weld zone, such as a crack or a burn-through, degrades the welded material strength. Therefore, a tension test is performed to ascertain whether a weld has defects. The tension tester used in this experiment is an Autograph AG-X (Shimadzu Corpration). The 


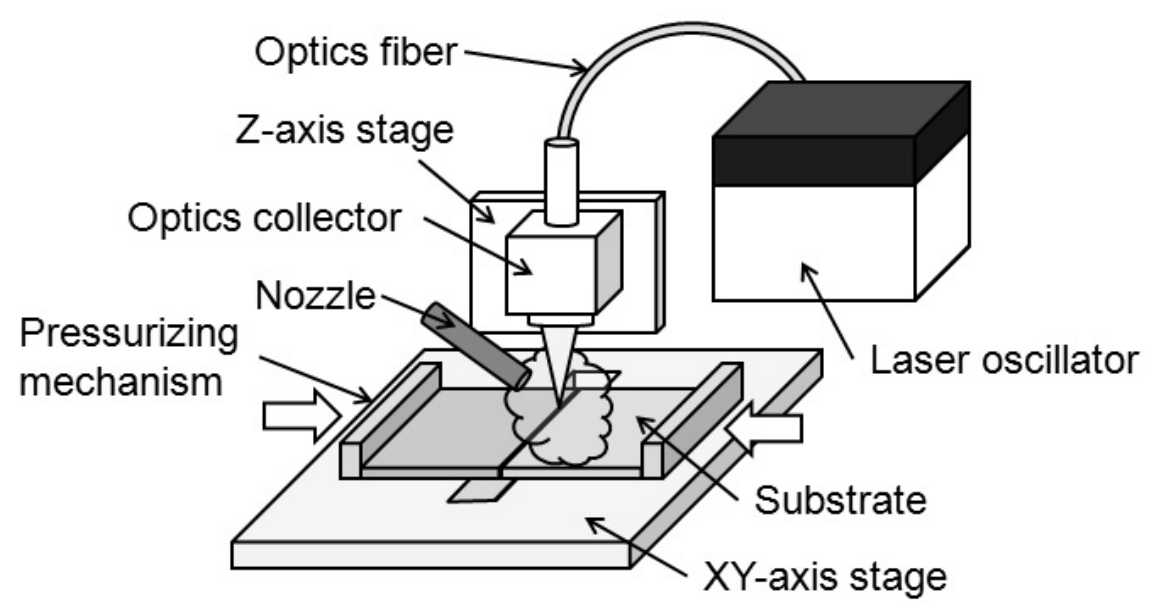

Fig. 1 Experimental apparatus of laser butt welding

weld width of test piece is cut to $5 \mathrm{~mm}$, the parallel part length of the test piece is $50 \mathrm{~mm}$. The test speed is $10 \mathrm{~mm} \cdot \mathrm{min}^{-1}$.

(2) Vickers hardness test

The Vickers hardness of the test pieces is measured because brass may be softened by exposure to heat during welding. The Vickers hardness tester is a microhardness tester FM-800 (Futuertech Corporation). The cross section of the weld samples was polished in advance. The test load is $1.96 \mathrm{~N}$ and the retention time is $10 \mathrm{~s}$.

(3) Airtight test

An airtightness test was performed to verify the airtightness of the weld. A weld sample is attached to each side of the test container. The weld samples are immersed in a water tank subjected to pressure, and the setup is visually inspected for signs of gas leaks. The test condition is $2 \mathrm{~min}$ in nitrogen at $1.0 \mathrm{MPa}$.

(4) Heat cycle test

A liquid-liquid heat exchanger is assumed and a heat cycle test is performed. A test piece is fixed at either end and subjected to a temperature cycle ranging from $-20^{\circ} \mathrm{C}$ to $120^{\circ} \mathrm{C}$ in an environmental testing machine (SH-241, Espec Company). After up to 500 cycles, the test pieces are visually inspected and then their strength is evaluated by a tension test.

\section{Laser welding examination}

Laser welding is examined to understand the range of processing conditions under which laser butt welding of stainless steel and brass is possible by changing each parameter. The parameters include laser irradiation position, amount of defocus, laser power, and welding speed. The surface of each test piece welded under each condition is polished and observed through an optical microscope.

\subsection{Influence of the laser irradiation position}

Brass is very different from stainless steel in terms of its dynamic material value. It is believed that the molten time affects the weld properties. Therefore, the irradiation position of the laser was moved to one side of the metal, and the condition of the weld was observed. The laser irradiation position relative to the boundary surface and the beam-centered distance is shown in Fig. 2 and is defined as "shift amount." In Fig. 2, the laser irradiation position has been shifted to the brass side. 


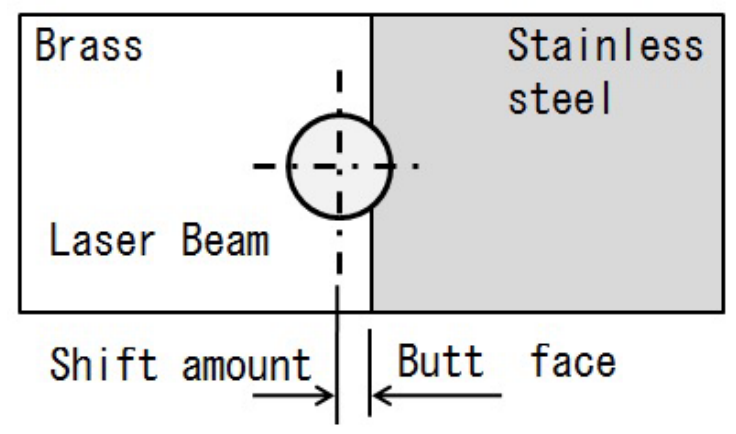

Fig. 2 Laser beam position at the welding

Figure 3 shows the state of weld beads for each laser irradiation position. The weld conditions are as follows: laser power: $750 \mathrm{~W}$, welding speed: $300 \mathrm{~mm} \cdot \mathrm{min}^{-1}$, and defocus: $0.5 \mathrm{~mm}$ to the upper part. The beam diameter (1/e2) as measured in a beam profiler is 0.32 $\mathrm{mm}$. The shift amounts are (a) $0.4 \mathrm{~mm}$ to the stainless steel side, (b) $0.2 \mathrm{~mm}$ to the stainless steel side, (c) $0 \mathrm{~mm}$, and (d) $0.2 \mathrm{~mm}$ to the brass side.

The shift amounts under which welding was possible were $0.9 \mathrm{~mm}$ to the stainless steel side and $0.4 \mathrm{~mm}$ to the brass side. In the case of shift amounts of $0.2 \mathrm{~mm}, 0.4 \mathrm{~mm}$, and 0 $\mathrm{mm}$ on the stainless steel side, the width of the weld beads is $0.8-1 \mathrm{~mm}$. The weld beads are intensely rough and spatter is scattered around the perimeter, and some blowholes shown in (a) are observed. When the shift amount is to the stainless steel side, weld beads is the same tendency. In contrast, for a shift amount of $0.2 \mathrm{~mm}$ to the brass side, the width of the weld beads is approximately $0.5 \mathrm{~mm}$, which is smaller than the shift is to the stainless steel side. In addition, most of the weld beads are smooth and no blowholes are observed. When the shift amount is to the brass side, weld beads is the same tendency.

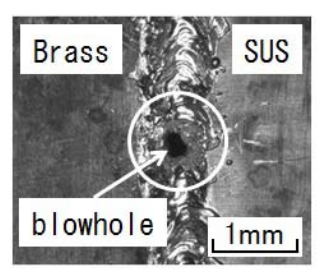

(a) SUS side $0.4 \mathrm{~mm}$

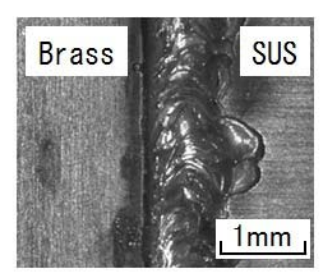

(b) SUS side $0.2 \mathrm{~mm}$

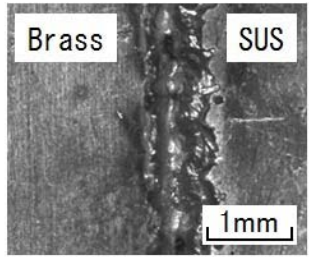

(c) Butt face

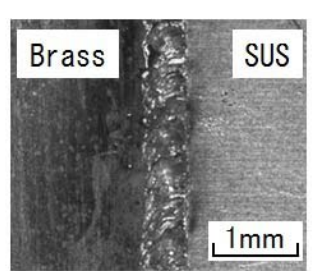

(d) Brass side $0.2 \mathrm{~mm}$

Fig. 3 Photographs of weld beads for laser irradition position

Figure 4 shows the photographs of weld cross sections at each laser irradiation position. The shift amounts are (a) $0.4 \mathrm{~mm}$ to the stainless steel side, (b) $0.2 \mathrm{~mm}$ to the stainless steel side, (c) $0 \mathrm{~mm}$, and (d) $0.2 \mathrm{~mm}$ to the brass side. In the cases of shifts of $0.2 \mathrm{~mm}$ and 0.4 $\mathrm{mm}$ to the stainless steel side, underfilling increased in the upper and lower parts of the weld, and the cross section became half the weld sample thickness. A pattern in which brass and stainless steel are mixed is particularly observed on the brass side of the weld. In the case of a shift amount of $0 \mathrm{~mm}$, underfilling is smaller than that with a shift to the stainless steel side, but there are blowholes in the weld. A pattern in which brass and stainless steel are mixed is also seen when there is a shift to the stainless steel side. In contrast, with a 0.2 $\mathrm{mm}$ shift to the brass side, brass melts mainly in the weld, and the brass-stainless steel mixture pattern, such as when there is a shift to the stainless steel side and when the shift amount is $0 \mathrm{~mm}$, is hardly found. In addition, defects such as blowholes are not found. When shift aomunt is $0 \mathrm{~mm}$ and stainless steel side, it is thought that the brass contacting to stainless steel suddenly does temperature rise to the fusing point of the stainless steel because stainless steel melts earlier. The melting point of stainless steel is $1726 \mathrm{~K}$ and is a 


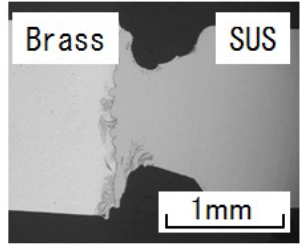

(a) SUS side $0.4 \mathrm{~mm}$

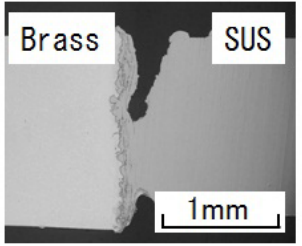

(b) SUS side $0.2 \mathrm{~mm}$

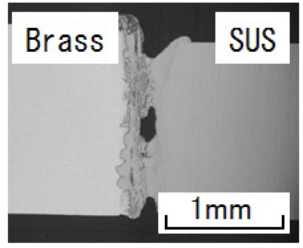

(c) Butt face

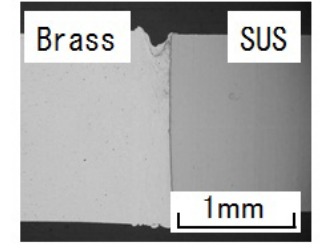

(d) Brass side $0.2 \mathrm{~mm}$

Fig. 4 Microphotographs of weld cross sections at each laser irradiation position

high temperature more than $500 \mathrm{~K}$ than the fusing point of zinc included in brass. In addition, it seems that the zinc vaporizes in the whole weld because big stirring is seen in the weld. Therefore it is thought that sudden volatilization of zinc causes blowhole and underfilling.

\subsection{Influence of defocus}

The laser energy density affects the working quality. Therefore, we altered the energy density by changing the focus position and welded the test pieces under each condition. The amount of change in the focus position is defined as "defocus" and is expressed by $(+)$ for a shift to the upper part and by (-) for a shift to the lower part. The defocus is based on the surface of the test piece $(=0 \mathrm{~mm})$.

Figure 5 shows the state of weld beads when the defocus is changed. The welding conditions are as follows: laser power: $750 \mathrm{~W}$, welding speed: $300 \mathrm{~mm} \cdot \mathrm{min}^{-1}$, and shift amount: $0.2 \mathrm{~mm}$ to the brass side. In (a), the defocus is $0.0 \mathrm{~mm}$ and a bead width of $0.4 \mathrm{~mm}$ is the narrowest. The energy density in the weld sample surface was highest, but burn-through was not found. However, the weld bead was discolored black. In (b), (c), and (d), the defocus is $2.0 \mathrm{~mm}, 3.0 \mathrm{~mm}$, and $4.0 \mathrm{~mm}$, respectively. The defocus increases with the bead width. The bead width is uneven at a defocus of $4 \mathrm{~mm}$. In addition, a weld is not produced when the defocus exceeds $5 \mathrm{~mm}$. When the defocus is in the negative direction, it shows the same tendency as that in the positive direction, and when the defocus exceeds 4 $\mathrm{mm}$, the weld is not produced.

Figure 6 shows the photographs of weld cross sections when the defocus is changed. In (a) - (d), the defocus is $0 \mathrm{~mm}, 2 \mathrm{~mm}, 3 \mathrm{~mm}$, and $4 \mathrm{~mm}$, respectively. In (a) - (c), the weld

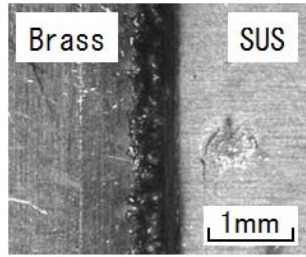

(a) $0.0 \mathrm{~mm}$

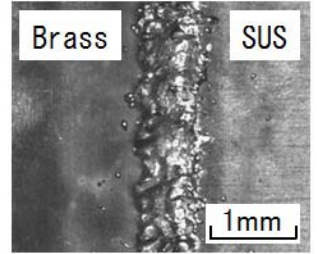

(b) $2.0 \mathrm{~mm}$

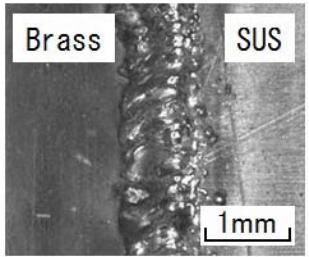

(c) $3.0 \mathrm{~mm}$

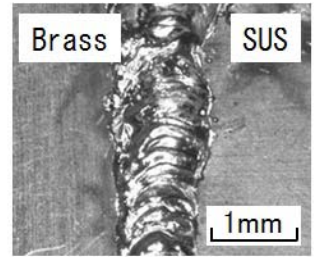

(d) $4.0 \mathrm{~mm}$

Fig. 5 Photographs of weld beads when the defocus is changed

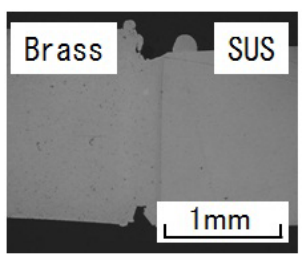

(a) $0.0 \mathrm{~mm}$

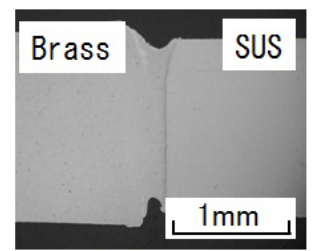

(b) $2.0 \mathrm{~mm}$

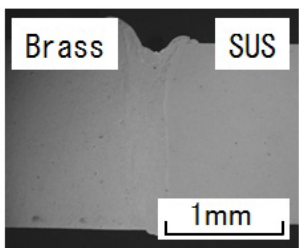

(c) $3.0 \mathrm{~mm}$

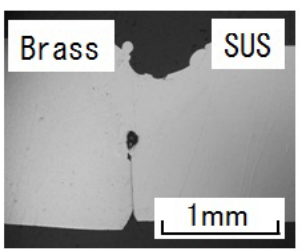

(d) $4.0 \mathrm{~mm}$

Fig. 6 Microphotographs of weld cross sections when the defocus is changed 
width changes, but the brass-stainless steel mixture pattern is not found, and become the section of similar form. In (d), penetration is only half, approximately $0.75 \mathrm{~mm}$, the sample thickness, and unlike (a)-(c), there are more number of stainless steel melts than brass melts in the upper part.

\subsection{Influence of laser power}

In laser welding, when the laser power is too low, a weld is not formed, and when the laser power is too high, burn-throughs or cracks occur. Therefore, an appropriate laser power range needs to be identified. Figure 7 shows the state of weld beads when the laser power is changed. The welding conditions are as follows: welding speed: $300 \mathrm{~mm} \cdot \mathrm{min}^{-1}$, defocus: $+0.5 \mathrm{~mm}$, shift amount: $0.2 \mathrm{~mm}$ to the brass side. In (a)-(d), the laser power is 250 , 300,500 , and $1000 \mathrm{~W}$, respectively. A weld cannot be formed when the laser power is less than $200 \mathrm{~W}$. Moreover, burn-throughs do not occur even at a maximum laser power of 1000 W. Under conditions of 250-1000 W, neither blowholes nor cracks occur in the weld beads, and the bead width changes slightly from 0.4 to $0.5 \mathrm{~mm}$.

Figure 8 shows the photographs of weld cross section when the laser power is changed. In (a)-(d), the laser power is $250,300,500$, and $1000 \mathrm{~W}$, respectively. In (a), penetration is about $1 \mathrm{~mm}$ and does not reach the base. For a laser power of more than $300 \mathrm{~W}$, mainly brass melts in the weld and the brass-stainless steel mixture pattern in the weld is not found. In addition, blowholes or cracks do not occur in the weld.

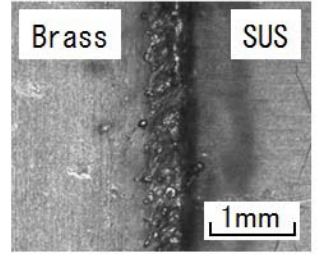

(a) $250 \mathrm{~W}$

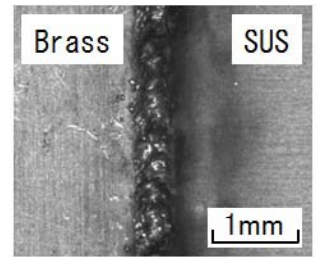

(b) $300 \mathrm{~W}$

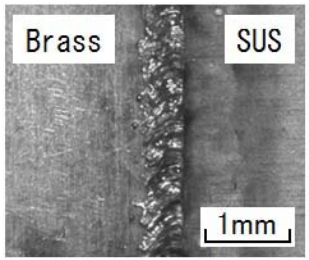

(c) $500 \mathrm{~W}$

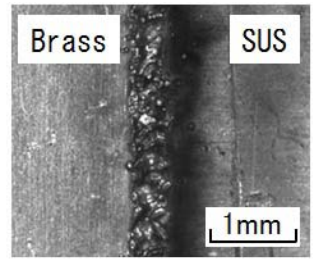

(d) $1000 \mathrm{~W}$

Fig. 7 Photographs of weld beads when the laser power is changed

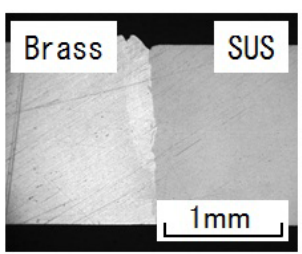

(a) $250 \mathrm{~W}$

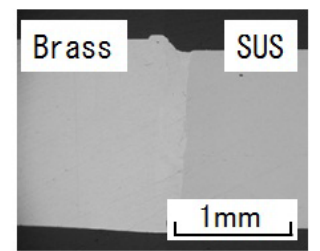

(b) $300 \mathrm{~W}$

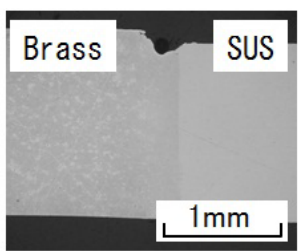

(c) $500 \mathrm{~W}$

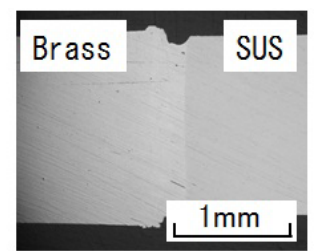

(d) $1000 \mathrm{~W}$

Fig. 8 Microphotographs of weld cross sections when the laser power is changed

\subsection{Influence of welding speed}

Welding speed is a parameter that indicates the amount of energy spent per unit length. Figure 9 shows the state of weld beads when the welding speed is changed. The welding conditions are as follows: laser power: $750 \mathrm{~W}$, defocus: $+0.5 \mathrm{~mm}$, and shift amount: $0.2 \mathrm{~mm}$ to the brass side. In (a)-(d), the welding speed is $150 \mathrm{~mm} \cdot \mathrm{min}^{-1}, 600 \mathrm{~mm} \cdot \mathrm{min}^{-1}, 1200 \mathrm{~mm}$. $\mathrm{min}^{-1}$, and $1800 \mathrm{~mm} \cdot \mathrm{min}^{-1}$, respectively. In the range of $150-1200 \mathrm{~mm} \cdot \mathrm{min}^{-1}$, differences in appearances such as width or the geometry of the weld bead are not observed, and cracks or blowholes do not occur. At $1800 \mathrm{~mm} \cdot \mathrm{min}^{-1}$, there is a wide point on the weld bead, and the configuration of the bead becomes unstable.

Figure 10 shows the photographs of weld cross sections when the welding speed is changed. In (a)-(d), the welding speeds are $150 \mathrm{~mm} \cdot \mathrm{min}^{-1}, 600 \mathrm{~mm} \cdot \mathrm{min}^{-1}, 1200 \mathrm{~mm} \cdot \mathrm{min}^{-1}$, 
and $1800 \mathrm{~mm} \cdot \mathrm{min}^{-1}$, respectively. With a welding speed of $150-1200 \mathrm{~mm} \cdot \mathrm{min}^{-1}$, brass mainly melts in the weld, and the brass-stainless steel mixture pattern in the weld is not found. In addition, blowholes or cracks do not occur in the weld. At a welding speed of $1800 \mathrm{~mm} \cdot \mathrm{min}^{-1}$, penetration is around $0.9 \mathrm{~mm}$ and does not reach the base.

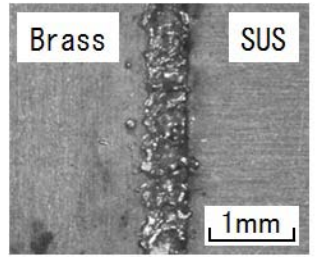

(a) $150 \mathrm{~mm} \cdot \mathrm{min}^{-1}$

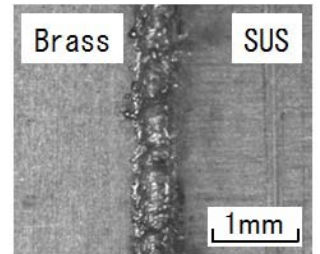

(b) $600 \mathrm{~mm} \cdot \mathrm{min}^{-1}$

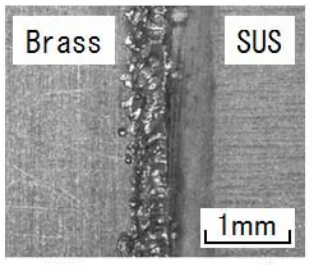

(c) $1200 \mathrm{~mm} \cdot \mathrm{min}^{-1}$

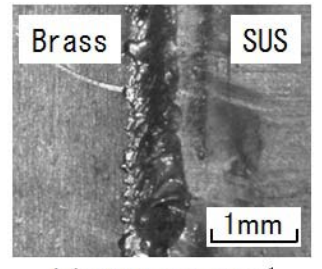

(d) $1800 \mathrm{~mm} \cdot \mathrm{min}^{-1}$

Fig. 9 Photographs of weld beads when the welding speed is changed

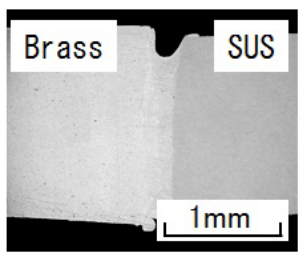

(a) $150 \mathrm{~mm} \cdot \mathrm{min}^{-1}$

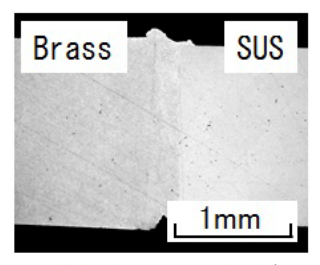

(b) $600 \mathrm{~mm} \cdot \mathrm{min}^{-1}$

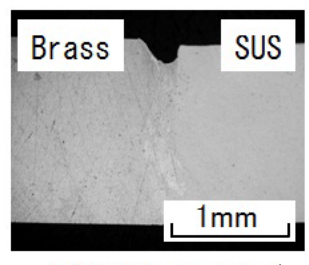

(c) $1200 \mathrm{~mm} \cdot \mathrm{min}^{-1}$

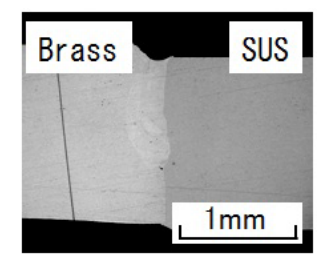

(d) $1800 \mathrm{~mm} \cdot \mathrm{min}^{-1}$

Fig. 10 Microphotographs of weld cross sections when the welding speed is changed

\section{Evaluation of welding characteristics}

\subsection{Tension test result}

We evaluate the weld strength by performing tension tests about the bondable condition of each parameter. Figure 11 shows the relationship between breaking strength and the laser irradiation position. The weld samples are the same as in Section 3.1. The number of weld samples is five under each condition. The breaking strength of stainless steel is $570 \mathrm{MPa}$ and that of the brass-base material is $350 \mathrm{MPa}$. In addition, the breaking strength of brass during annealing is $275 \mathrm{MPa}$. When the irradiation position shifts to the brass side, a weld sample separates from the brass base material and breaks at the weld when the shift amount is $0.1-0.2 \mathrm{~mm}$, although the strengths of all weld samples are greater than the breaking strength of $350 \mathrm{MPa}$. When the shift amount is $0.3 \mathrm{~mm}$ to the brass side, all weld samples break at the weld, and some samples have a breaking strength of less than $350 \mathrm{MPa}$. When the shift amount is $0.4 \mathrm{~mm}$ to the brass side, the breaking strength is less than $100 \mathrm{MPa}$ for all weld samples. At all test piece with shift amount $0 \mathrm{~mm}$, the breaking strength is less than $300 \mathrm{MPa}$. When the irradiation position shifts to the stainless steel side by 0.2-0.4 mm, some samples have breaking strengths in excess of 350 $\mathrm{MPa}$; however, the breaking strength of some weld samples is less than $300 \mathrm{MPa}$. With a shift amount of 0.6-0.8 mm, all weld samples break from the weld, where the breaking strength is less than $275 \mathrm{MPa}$. As a result, it was found that good breaking strength is obtained when the shift amount is $0.1-0.2 \mathrm{~mm}$ on the brass side. When shift aomunt is $0 \mathrm{~mm}$ and stainless steel side, blowhole and underfill shown in Fig. 3 and Fig.4 occur. Therefore it is thought that the crosssection of weld becomes small and breaking strength decreases. In contrast, when shift amount is brass side, mixture of stainless steel and the brass shown in Fig.4(d) does not occur in weld. Therefore the weld is almost brass, and it is thought that the breaking strength becomes at the same level as brass. 


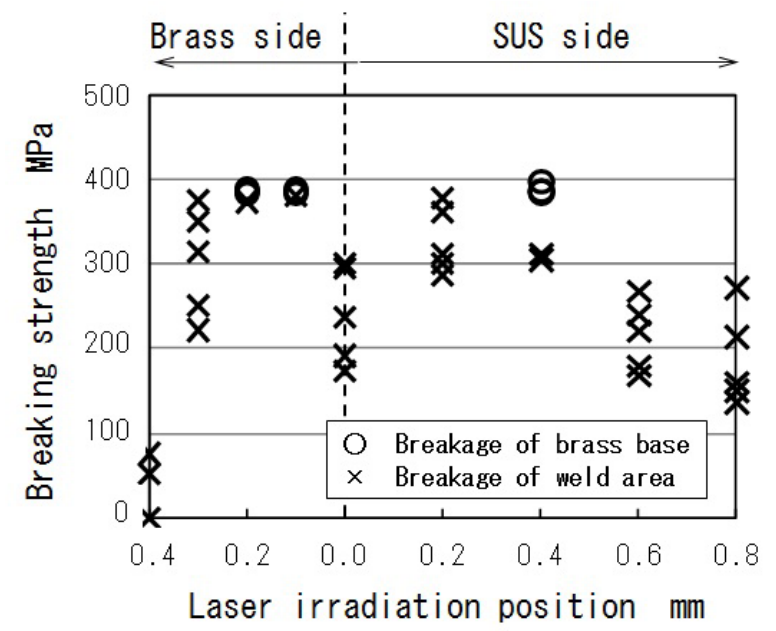

Fig. 11 Relationship between breaking strength and the laser irradiation position

Figure 12 shows the relationship between breaking strength and the amount of defocus. The weld samples are the same as in Section 3.2. The number of weld samples is five under each condition. The amount of defocus ranges from $-3.5 \mathrm{~mm}$ to $+3.5 \mathrm{~mm}$. The weld samples have a breaking strength of less than $350 \mathrm{MPa}$, but all samples have a breaking strength of more than $275 \mathrm{MPa}$ during annealing. When the defocus is $-4.0 \mathrm{~mm}$ or $4.0 \mathrm{~mm}$, penetration is half of the weld sample thickness, and hence, the breaking strength is less than $50 \mathrm{MPa}$.

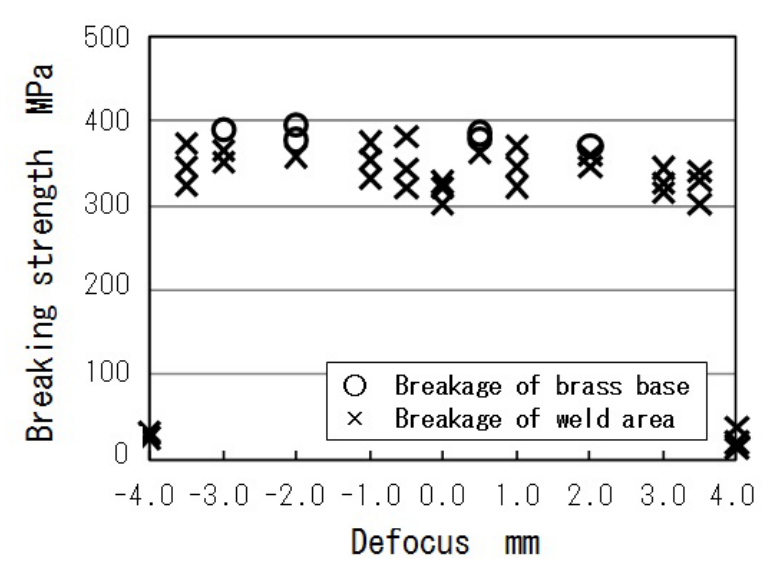

Fig. 12 Relationship between breaking strength and the amount of defocus

Figure 13 shows the relationship between breaking strength and the laser power. The weld samples are the same as in Section 3.3. The number of weld samples is five under each condition. When the laser power is $300 \mathrm{~W}$ or higher, the breaking strength of all weld samples is greater than $275 \mathrm{MPa}$. When the laser power is $750 \mathrm{~W}$, the breaking strength is greater than $350 \mathrm{MPa}$. Furthermore, when the laser power is $250 \mathrm{~W}$, the breaking strength is less than $275 \mathrm{MPa}$; this is because penetration is $1 \mathrm{~mm}$, i.e., two-third the weld sample thickness.

Figure 14 shows the relationship between breaking strength and the welding speed. The weld samples are the same as in Section 3.4. The number of the weld samples is five under each condition. The welding speed is less than $275 \mathrm{MPa}$ with some samples welded at 150 $\mathrm{mm} \cdot \mathrm{min}^{-1}$. The welding speed is more than $275 \mathrm{MPa}$ with all weld samples in the range of $300-1500 \mathrm{~mm} \cdot \mathrm{min}^{-1}$. In addition, penetration is $0.9 \mathrm{~mm}$, i.e., $60 \%$ of the stock thickness at $1800 \mathrm{~mm} \cdot \mathrm{min}^{-1}$ and the breaking strength is less than $275 \mathrm{MPa}$. 


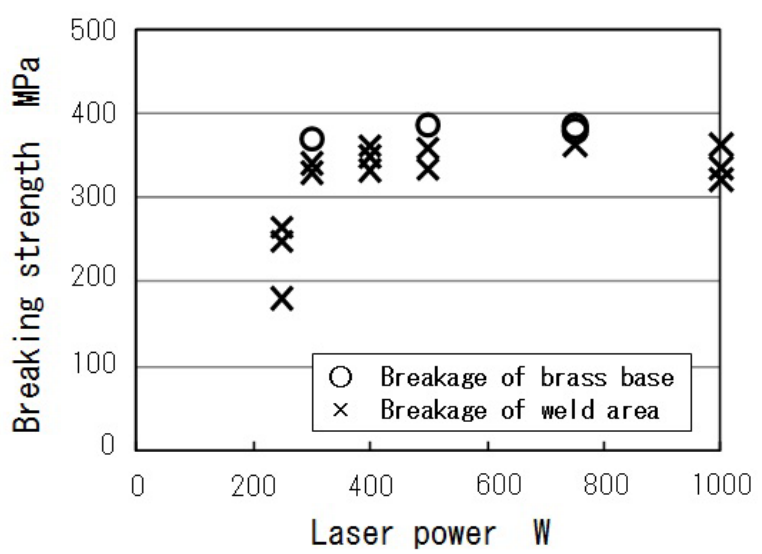

Fig. 13 Relationship between breaking strength and the laser power

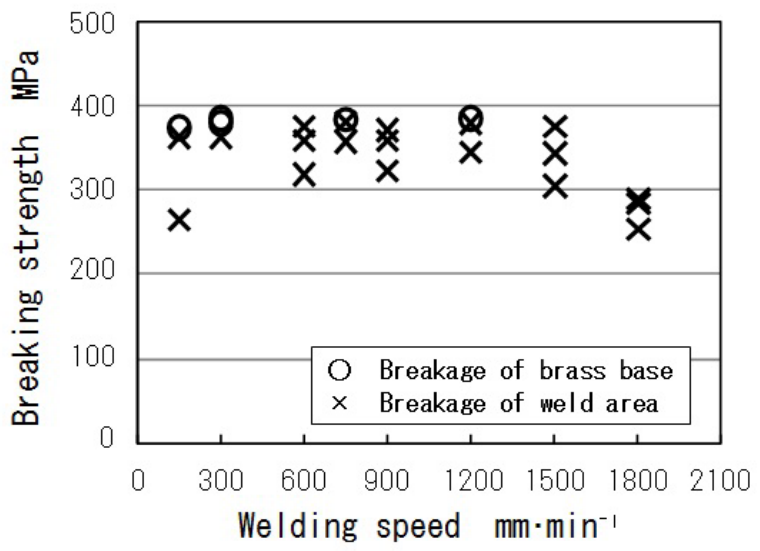

Fig. 14 Relationship between breaking strength and the welding speed

\subsection{Hardness test result}

Copper alloys such as brass are annealed by heating, and their strength may decrease as a result of softening. Therefore, the Vickers hardness of each weld sample is measured. Figure 15 shows the results of the Vickers hardness measurement of the weld samples. The results for welded copper and stainless steel are shown together. In the case of a weld

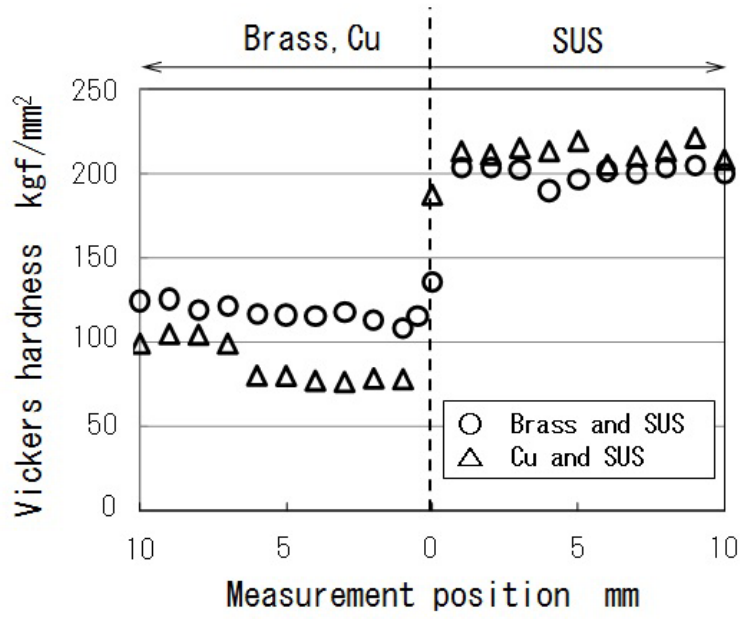

Fig. 15 Influence of heat at the weld on hardness of weld sample 
sample of copper and stainless steel, the weld sample hardness reduces in the range 6-7 mm on the copper side to about $70 \%$ of the base material hardness (100 Hv). In contrast, generally, the hardness of the weld sample of brass and stainless steel is approximately at the same level as that $(115 \mathrm{Hv})$ of the base material. In the case of weld of copper and stainless steel, copper base is broken in a tension test because copper is softened at the heat of weld. In contrast, it was understood that brass did not soften in welding heat. As a result, it is thought the weld was broken in the tension test because the cross section of the weld was decreased.

\subsection{Airtightness test result}

As it is important that airtightness is maintained in a welded pipe, an airtightness test was performed. The welding conditions are as follows: laser power: $750 \mathrm{~W}$, welding speed: $300 \mathrm{~mm} \cdot \mathrm{min}^{-1}$, and defocus: $+0.5 \mathrm{~mm}$. The shift amounts are $0.2 \mathrm{~mm}$ on the brass side and $0.0 \mathrm{~mm}$ and $0.2 \mathrm{~mm}$ and $0.4 \mathrm{~mm}$ on the stainless steel side. The number of weld samples is five under each condition. The results show that when the shift amount on the brass side is $0.2 \mathrm{~mm}$, no leaks were detected; however, with shift amounts of $0 \mathrm{~mm}$ and $0.2 \mathrm{~mm}$ and $0.4 \mathrm{~mm}$ on the stainless steel side, leaks were detected in all weld samples. After observing the leaked points, blowholes were detected in the beads as shown in Figs. 3(a) and (c).

\subsection{Heat cycle test result}

Figure 16 shows the photographs of weld beads before and after the heat cycle test: (a) before test, (b) after 100 cycles, (c) after 250 cycles, and (d) after 500 cycles. The welding conditions are as follows: laser power: $750 \mathrm{~W}$, welding speed: $300 \mathrm{~mm} \cdot \mathrm{min}^{-1}$, defocus: +0.5 $\mathrm{mm}$, and shift amount: $0.1 \mathrm{~mm}$ to the brass side. The results showed that there was no evidence of cracking.

Figure 17 shows the breaking strength of the weld samples before and after the heat cycle test. Even after being subjected to a temperature cycle, the breaking strength was

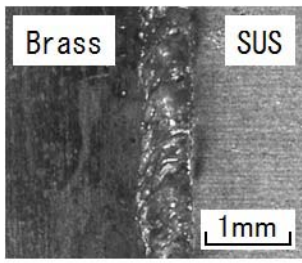

(a) Before test

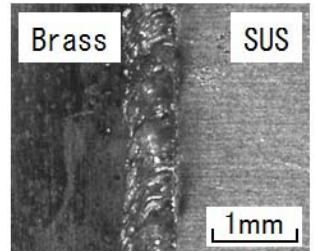

(b) After $100 \mathrm{cycle}$

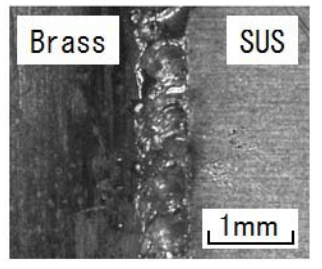

(c) After 250cycle

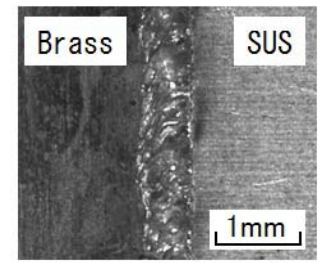

(d) After 500cycle

Fig. 16 Photographs of weld beads before and after the heat cycle test

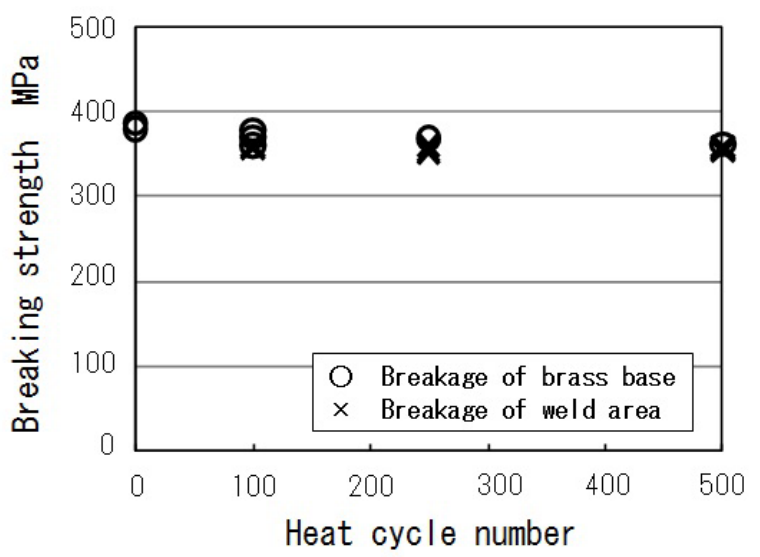

Fig. 17 Relationship between the heat cycle and strength 
more than $275 \mathrm{MPa}$, and there was no significant change. The thermal expansion coefficient of stainless steel is $17.3 \times 10^{-6} / \mathrm{K}$ and that of brass is $17.5 \times 10^{-6} / \mathrm{K}$. In the temperature range used in a liquid-liquid heat exchanger, it was found that the heat cycle did not influence the strength.

\section{Conclusion}

In this study, butt welding of $1.5 \mathrm{~mm}$ stainless steel and brass plates was performed using a YAG disk laser under a number of welding conditions, and the mechanical properties of the welds were evaluated. From the results, the following can be concluded.

(1) Butt welding of brass and stainless steel can be performed without reducing the strength of the materials by shifting the laser irradiation position to the brass side by $0.1-0.2 \mathrm{~mm}$.

(2) When shifting the laser irradiation position by $0.2 \mathrm{~mm}$ to the brass side, a good weld is possible using a laser power of more than $300 \mathrm{~W}$, a welding speed of less than 1200 $\mathrm{mm} \cdot \mathrm{min}^{-1}$, and a defocus ranging from $-3.5 \mathrm{~mm}$ to $+3.5 \mathrm{~mm}$.

(3) When brass and stainless steel is butt welded using a laser power of $750 \mathrm{~W}$, a welding speed of $300 \mathrm{~mm} \cdot \mathrm{min}^{-1}$, a defocus of $+0.5 \mathrm{~mm}$, and a shift amount of $0.2 \mathrm{~mm}$ to the brass side, most of the softening does not occur on the brass side even after welding.

(4) When brass and stainless steel is butt welded using a laser power of $750 \mathrm{~W}$, a welding speed of $300 \mathrm{~mm} \cdot \mathrm{min}^{-1}$, a defocus of $+0.5 \mathrm{~mm}$, and a shift amount of $0.2 \mathrm{~mm}$ to the brass side, even if nitrogen at $1.0 \mathrm{MPa}$ is supplied to the weld for $2 \mathrm{~min}$, gas leaks are not observed.

(5) When brass and stainless steel is butt welded at a laser power of $750 \mathrm{~W}$, a welding speed of $300 \mathrm{~mm} \cdot \mathrm{min}^{-1}$, a defocus of $+0.5 \mathrm{~mm}$, and a shift amount of $0.2 \mathrm{~mm}$ to the brass side, even if a temperature cycle of $-20^{\circ} \mathrm{C}$ to $120^{\circ} \mathrm{C}$ is performed 500 times, cracks do not occur and the weld strength does not decrease.

It was felt uneasy about that void nucleation by the volatilization of the zinc in the brass extremely had decreased weld strength. However, it was not recognized by an evaluation effect and strength test depending on a working condition in this study. It is thought that it is one characteristic of the laser welding by high-speed melting and cooling. Welding mechanism is plan to be investigated in detail in future by analyzing.

Finally, I thank the members of Production System Laboratory of Hitachi Metal Ltd. for their cooperation in this study.

\section{References}

(1) MASUMOTO, H. et al: Diffusion Bonding between Copper-Beryllium Alloy and Stainless steel, Quarterly Journal of The Japan Welding Society, 13-3 (1995) 411 (in Japanese)

(2) HIRAISHI, M. et al: Laser Lap-Welding of Stainless Steel to Cu Alloy, Quarterly Journal of The Japan Welding Society, 17-3, (1999), 420-425. (in Japanese)

(3) YAMAMOTO, H. and IKENO, J.: A Research on Laser Micro-Joining between Different Metals using YAG Laser, JSPE Autumn meeting, (2002), 374.

(4) SASAKI, M. and IKENO, J.: Laser welding of metal materials of different types, Journal of the Japan Society for Abrasive Technology, 55-6 (2011), 348-353. (in Japanese)

(5) KATAYAMA, S.: Formation Mechanism and Prevention Technique of Laser Welding Imperfection, Quarterly Journal of The Japan Welding Society, 19-1 (2001), 213-218. (in Japanese)

(6) The Japan Institute of Metals, The Iron and Steel Institute of Japan: Steel Material Handbook, Maruzen Company, Ltd., (1974), 618 (in Japanese)

(7) KUBO,R. et al: Iwanami physics and chemistry dictionary, Iwanami Shoten Publisher, (1987), 880 (in Japanese) 